\title{
Massive osteolysis of the skull and its therapeutic implications: a case report
}

\author{
CORNELIS BOUWSMA,* GWAN GO, $\dagger$ AREND PANDERS, $\ddagger$ COEN SCHOOTS, $\S$ \\ LOUK VENCKEN.\|
}

From the Departments of Neurology, ${ }^{*}$ Neurosurgery, $\dagger$ Maxillofacial Surgery, $\ddagger$ Pathology $§$ and Neuroradiology,\| University Hospital, Groningen, The Netherlands

SUMMARY A case of massive osteolysis of the skull and its histology is described. Removal of the bone defect with a margin of normal bone and covering of the defect by cranioplasty is advised and may arrest the disease.

Massive osteolysis is an entity of unknown aetiology. To our knowledge there have been few reports of the disease in the skull. ${ }^{1-3}$ Here we describe a further case localised to the skull.

\section{Case report}

When aged 9 years the patient was in 1973 first referred to a neurologist because of headaches. A small left parietal bone defect was found on palpation, although it was hardly visible on radiographs of the skull. A relationship with the headaches was doubted. There was no history of injury or of other causative factors. As the defect had gradually grown in size he was referred to our outpatient department in 1987. Physical examination was unremarkable. In the left parietal area a bone defect could be palpated, measuring $3 \times 4 \mathrm{~cm}$. Total blood count, erythrocyte sedimentation rate, plasma calcium, alkaline phosphatase and Treponema pallidum haemagglutination tests were normal. The skull radiographs showed a defect much larger than that of 1973. CT (fig 1) revealed the lesion to be restricted to the outer table; no intracranial abnormality was seen. The total body bone scan was unremarkable.

As the cause of the bone defect was not evident, a biopsy specimen was obtained. Under general anaesthesia biopsy was performed on the periosteum and the border of the defect. Histology of the bone specimen revealed the diagnosis of massive osteolysis (see below). As the inner table was very thin, there was a risk of fracturing from trivial injuries with consequent damage to the underlying cerebral cortex. Further progression would only increase this risk. At a second intervention therefore the entire bone defect was removed

\footnotetext{
Address for reprint requests: Cornelis Bouwsma, Department of Neurology, University Hospital Groningen, Oostersingel 59, 9700 RB Groningen, The Netherlands.
}

Received 6 August 1988 and in revised form 12 September 1988. Accepted 6 October 1988 including a margin of normal bone. Postoperative course was uneventful and the skull defect was protected by an external plastic helmet. Later an acrylic plate was implanted in the defect. As yet, follow up (8 months) has shown no change; only time will reveal whether the disease has arrested.

\section{Examination of the specimen}

Macroscopic examination showed a lesion measuring $5.5 \times 5$ $\mathrm{cm}$ (fig $2 \mathrm{a}$ ). While the border was $6 \mathrm{~mm}$ thick, the centre was thin like parchment and translucent. The places of the earlier biopsies were recognised on the border of the specimen. The transition from thick to thin bone was characterised by a more or less circular, $5 \mathrm{~mm}$ broad red zone with an irregular surface.

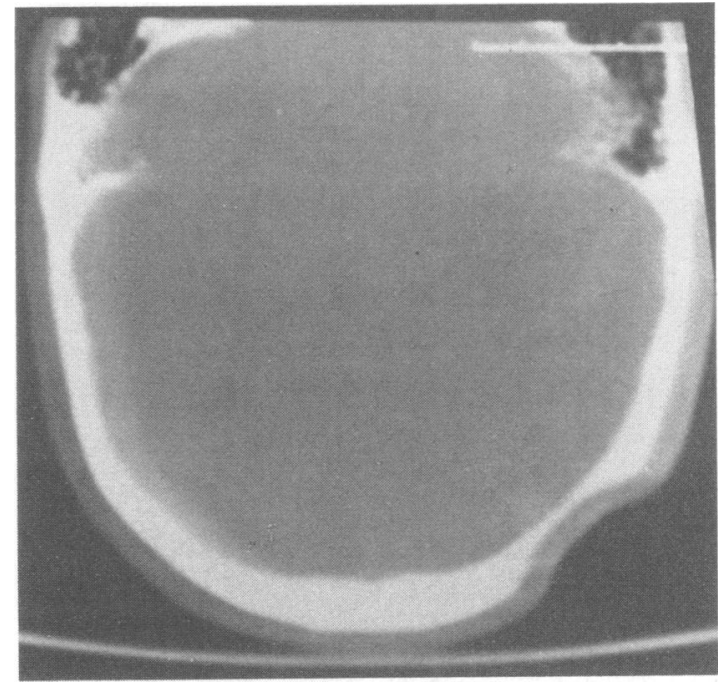

Fig 1 CT scan of the skull: left parietal bone defect, the inner table; appears to be intact. 


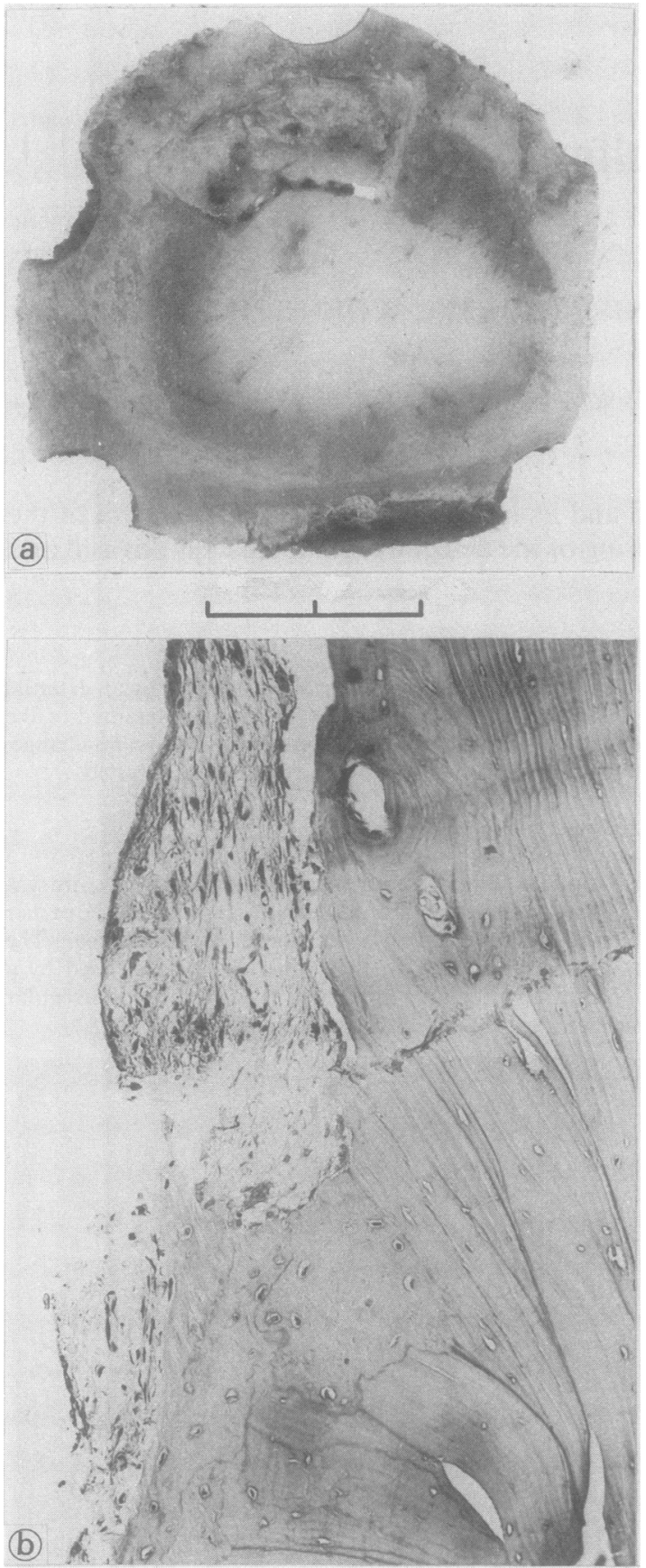

Fig 2 (a) The excised bone defect with a margin of normal bone. The dark zone marks the "red zone" around the defect. (b) Border of the defect showing absorption and remodelling of bone. Cementing lines are clearly visible.
Microscopic examination of the periosteum revealed some increase in vascularity. Signs of inflammation were absent. The border of the lesion showed lamellar bone tissue with remodelling. There was an increase in the number of irregular cementing lines (fig $2 \mathrm{~b}$ ). The bone marrow showed an abundance of fat with some focal haematopoetic tissue. A zone containing active osteoblasts was seen along the trabeculae. In the "red zone" the periosteum showed a large number of small vessels and a few scattered osteoblasts. The place of minimum bone thickness only consisted of compact bone tissue. There were no sigsn of malignancy. The clinical and radiological information as well as these findings conformed to those in massive osteolysis.

\section{Discussion}

Massive osteolysis of the skull is a rare entity. Most reports refer to localisation in the femur, humerus and the ribs, with few dealing with localisation in the skull. ${ }^{13}$ Although suspected, it is not clear if the osteoysis of the skull is related to osteolysis of femur and ribs. Abhyankar ${ }^{4}$ described a case associated with a meningeal sarcoma which was, however, at a site distant from the bone defect. The aetiology is unknown, but appears to be related to an active hyperaemia of bone. A relation to trauma has been suspected, but never proven. ${ }^{5}$ The osteolysis would then be mediated by a subperiosteal haematoma inducing it by the hyperaemia. According to Shafer the disease must be differentiated from infection, such ase osteomyelitis and from osteolysis associated with diseases of the nervous system such as tabes dorsalis syringomyelia, leprosy or myelodysplasia. ${ }^{6}$ The hise tological features have been well described. ${ }^{78}$ Treat? ment of the disease in other localisations has included radiotherapy ${ }^{8}$ as well as surgery. Kery reported the disease in the tibia, where it was arrested after early total resection. ${ }^{9}$

As to treatment of localisation in the skull, only Chai mentioned cranioplasty by "organic glass".' In one of his two cases the cranioplasty plate loosened. In the other the disease was arrested. As the course of the disease tends to be progressive, there is risk of minor trauma fracturing residual bone and the possibility of consequent cerebral complications. Therefore an expectant attitude does not seem warranted. As a first step in management a bone biopsy may be considered; this allows malignancies to be ruled out while a histological diagnosis can be made. In the case of massive osteolysis it is recommended to remove the bone defect, including the red zone, with a margin of normal bone during a second intervention. Eventually the resulting defect may be covered by cranioplasty. In our clinic we have excellent results using acrylic plastic to cover bone defects. Alternatives would be the use of cadaveric bone with demineralised paste. It is important that a margin of normal bone is included in the 
excision as otherwise the disease may progress, loosening the cranioplasty. In our case we seemed to have arrested the disease, but further follow up is required.

\section{References}

1 Chai WX, Wu JP, Chen KF. Massive osteolysis of the skull; long-term follow up observations after cranioplasty. Acta Neurochir 1984;73:201-6.

2 Heffez L, Doku HC, Carter BL, Feeney JE. Perspectives on massive osteolysis: report of a case and review of the literature. J Oral Surg 1983;55:331-43.

3 Iyer GV, Nayar A. Massive osteolysis of the skull. J Neurosurg 1975;34:92-4.
4 Abhyankar SC, Desai SR, Vast RR, Ramani PS. Massive osteolysis of skull associated with meningeal sarcoma. $J$ Indian Med Assoc 1985;83:67-9.

5 Ellis DJ, Adams TO. Massive osteolysis: report of a case. J Oral Surg 1971;29:659-63.

6 Shafer WG, Hine MK, Levy BM. A textbook of oral pathology. Philadelphia, WB Saunders Company, 4th ed 1983;693-4.

7 Frederiksen NL, Wesley RK, Sciubba JJ, Helfrick J. Massive osteolysis of the maxillofacial skeleton; a clinical, radiographic, histologic and ultrastructural study. J Oral Surg 1983;55:470-80.

8 Mathias K, Hoffmann J, Martin K. Gorham-Stout Syndrom der Mandibula. Radiologe 1986;26:439-59.

9 Kery L, Wouters HW. Massive osteolysis, report of two cases. J Bone Joint Surg 1970;52B:452-9. 